\title{
Dexamethasone effects on Bax expression in the mouse testicular germ cells
}

\author{
Hashemitabar Mahmoud ${ }^{1}$, Orazizadeh Mahmoud ${ }^{1}$, Khorsandi Layasadat ${ }^{1}$, \\ Albughobeish Naeim² \\ ${ }^{1}$ Department of Anatomical Sciences, Faculty of Medicine, Ahvaz Jundi-Shapour University of Medical \\ Sciences, Ahwaz - Iran \\ ${ }^{2}$ Department of Histology, Faculty of Veterinary Medicine, University of Shahid Chamran
}

\begin{abstract}
Exposure to glucocorticoids (GCs) leads to numerous changes in various biological systems including the reproductive system. The aim of the present study was to find out whether dexamethasone (Dex), a widely used GC, would influence the apoptosis and expression of Bax, an important proapoptotic protein, in the mouse testicular germ cells. Experimental groups of 8 male NMRI mice received one of the following treatments daily for 7 days: 4, $7 \mathrm{and} 10 \mathrm{mg} / \mathrm{kg}$ Dex. Control groups were treated with equivalent volumes of saline. Experimental and control animals were sacrificed $24 \mathrm{~h}$ after the last injection. Immunohistochemical procedure was used to evaluation of Bax expression and the deoxyuridine nick-end labeling (TUNEL) was applied to assessment of the apoptotic germ cells. Bax expression was upregulated mainly at stages VII-VIII of spermatogenic cycle $(p<0.05)$ in experimental groups. Apoptotic index was significantly increased in 7 and 10 $\mathrm{mg} / \mathrm{kg}$ Dex treated mice $(\mathrm{p}<0.05)$. It appears that GCs such as Dex could induce apoptosis through the expression of proapoptotic proteins.
\end{abstract}

Keywords: apoptosis, dexamethasone, germ cells, Bax

\section{Introduction}

GCs are extraordinary hormones that influence the activity of almost every cell in the body. They modulate the expression of approximately $10 \%$ of our genes, and are essential for life but are also increasingly implicated in the pathogenesis of disease and produce many unwanted effects when given therapeutically [1]. In therapeutic concentrations, GCs are strongly immunosuppressive and anti-inflammatory, which has made them one of the most prescribed drugs worldwide [2].

Some evidences have been shown that elevation of GC concentration precedes a decline in testosterone concentration in the male. Presence of testosterone is essential for normal function and survival of the germ cells in seminiferous tubules [3-6]. It seems clear that, when the

Correspondence: K. Layasadat, Department of Anatomical Sciences, Faculty of Medicine, Ahwaz Jundi-Shapour University of Medical Sciences Ahwaz - Iran, P.O. Box: 61335; tel.: 09161142321, fax.: 0611-3332036,

e-mail: layasadat@yahoo.com testicular environment can not support spermatogenesis, a specific pathway leading to germ cell apoptosis is activated [7].

Abnormally accelerated apoptosis of germ cells may lead to an imbalance of cell proliferation and death, resulting in spermatogenic impairment [6]. Two major proapoptotic pathways have been defined in mammalian cells. One initiated at the cell surface via FasL/Fas system and the second occurring in the mitochondria including Bax [8]. Bax translocates to the outer mitochondrial membrane and form a channel during apoptosis. Apoptotic signals cause to release cytochrome-c from this channel into the cytosol. In the cytosol cytochrome-c initiates a proteolytic cascade that leads to apoptotic cell death [9]. In present study, we have investigated the effects of Dex on apoptosis and expression of Bax in the mouse testicular germ cells.

\section{Materials and methods}

Animals. NMRI male mice weighing 25-30 g were kept in individual stainless steel cages under standardized conditions (constant 
temperature and humidity, 12-hour light-dark cycle). Food and water were freely available. The animals were randomly divided into six groups, each of 8 animals. The experimental groups (E1E3) received intrapritoneal injections of 4 (E1), 7 (E2) and 10 (E3) $\mathrm{mg} / \mathrm{kg}$ Dex (Dexamethasone phosphate dissolved in $0.9 \%$ saline) on 7 consecutive days. Control groups (C1-C3) were injected with $0.9 \%$ saline in equal volumes as for the experimental groups. Since TUNEL and immunohistochemical analysis showed no significant differences between three controls, all data were combined into one control group $(\mathrm{C})$. One day after the last injection animals were sacrificed by decapitation under ether anesthesia. The testes were excised, fixed in formalin solution for $48 \mathrm{~h}$ and embedded in paraffin wax. Five ?m-thick sections were prepared by using Leitz microtome for subsequent immunohistochemistry and deoxyUTP-digoxigenin nick end labeling (TUNEL) studies.

Immunohistochemistry. Five-micron thick tissue sections were deparaffinized in xylol and hydrated in decreasing series of ethanol. Endogenous peroxidase activity was blocked by incubation in methanol containing $0.3 \% \mathrm{H}_{2} \mathrm{O}_{2}$ for $15 \mathrm{~min}$ at room temperature, followed by a rinse in $0.1 \mathrm{M}$ phosphate buffered saline (PBS; $\mathrm{pH}$ 7.4) for $5 \mathrm{~min}$. The sections were then treated with citrate baffer $\left(\mathrm{pH}\right.$ 6) for $15 \mathrm{~min}$ at $98^{\circ} \mathrm{C}$ as antigen retrieval. Before application of specific primary antibodies, nonspecific background staining was prevented by incubation with goat serum diluted 1:10 $\mathrm{v} / \mathrm{v}$ in PBS for $50 \mathrm{~min}$. Then the sections incubated overnight at $4^{\circ} \mathrm{C}$ with primary antibodies, including the monoclonal antibody against Bax (Mouse Monoclonal anti-Bax; sc: 7480, Santa Cruz) at $1 / 100$ diluted in PBS containing 10\% normal goat serum (NGS). After washing twice with PBS the sections were incubated with secondary antibody biotinylated anti-mouse IgG (Santa Cruz ABC Peroxidase Mouse IgG Staining Kit) at $1 / 100$ for $50 \mathrm{~min}$. Then the speciments were incubated with peroxidase- conjugated avidinbiotin for $30 \mathrm{~min}$ at room temperature. After washing, the sections were incubated with diaminobenzidine (DAB) as chromogen, and counterstained with haematoxyline. Negative control was performed by omitting anti-Bax antibody. Mouse thymus was used as a positive control.

Three immunohistochemical slides from each animal were blindly assessed and staining intensity was estimated using a semiquantitative score, $\mathrm{H}$-score, as previously described [10,11].

The H-score was calculated for each section by application of the following algorithm:

\section{$\operatorname{HSCORE}=\Sigma \mathrm{Pi}(\mathrm{i}+1)$,}

where $\mathrm{i}$ is the intensity of staining ( 0 - no staining, 1 - weak, 2 - moderate, 3 - strong) and $\mathrm{Pi}$ is the percentage of stained cells for each intensity (0 to 100\%). For each mouse, at least 10 tubules/ stage were used. The stages were identified according to the criteria proposed by Russell and coworkers for paraffin sections. This method provides 12 stages of the spermatogenic cycle in mice [12]. $\mathrm{H}$-score assessment was repeated at least 3 times for each section by 3 workers.

Measurement of apoptosis. The deoxyuridine nick-end labeling (TUNEL) assay for apoptotic cell detection was performed with the In-Situ Cell Death Detection kit (POD kit, Roche, Germany). Briefly, dewaxed tissue sections were predigested with $20 \mu \mathrm{g} / \mathrm{ml}$ proteinase $\mathrm{K}$ for $20 \mathrm{~min}$ and incubated in phosphate buffered saline solution (PBS) containing $3 \% \mathrm{H}_{2} \mathrm{O}_{2}$ for 10 min to block the endogeous peroxidase activity. After incubating in $0.1 \%$ triton $\mathrm{X}-100$ in $0.1 \%$ sodium citrate for two min on ice $\left(4^{\circ} \mathrm{C}\right)$, the sections were incubated with the TUNEL reaction mixture, fluorescin-dUTP for $60 \mathrm{~min}$ at $37^{\circ} \mathrm{C}$. The slides were then rinsed three times with PBS and incubated with secondary antifluorescine-POD-conjugate for $30 \mathrm{~min}$. After washing three times in PBS, diaminobenzidineH2O2 (DAB, Santa Cruz, USA) chromogenic reaction was added to the sections. As a control for method specificity, the step using the TUNEL reaction mixture omitted in negative control section, and nucleotide mixture in reaction buffer was used instead. A cell was considered TUNEL-positive when the nuclear staining was intense, dark brown and homogenous. Apoptotic index (AI) was calculated by dividing the number of TUNEL-positive germ cells in a randomly focused seminiferous tubule by the total number of germ cells in that tubule and the result was multiplied by 100 . The AIs of 10 randomly selected tubules for each spermatogenic stage were evaluated and the mean AI of each case was calculated.

Statistical analysis. Data analysis was performed using ANOVA followed by LSD test. $\mathrm{P}<0.05$ was considered as the borderline of statistic significance.

\section{Results}

\section{Expression of Bax}

In $\mathrm{C}$ group, Bax was localized in cytoplasm and nucleus of spermatogonia (Fig. 1). In E1 group, the pattern of immunoreactivity in spermatogonia was similar to the $\mathrm{C}$ group. Weak immunoreactivity was observed in cytoplasm of spermatocytes. No detectable immunostaining was observed in spermatids (Fig. 2). H-score evaluation showed no significant difference in comparison to $\mathrm{C}$ group ( $\mathrm{p}>0.05)$. In $\mathrm{E} 2$ group, all types of germ cells showed positive immunostaining. The pattern of immunoreactivity in spermatogonia was similar to the $\mathrm{C}$ group. Bax localized in cytoplasm of some of the primary spermatocytes and spermatids (Fig. 3). Hscore evaluation showed the significant increase of Bax expression at stages IV-VI and VII-VIII of spermatogenic cycle $(\mathrm{p}<0.05)$.

In E3 group, all types of germ cells showed strong immunorectivity. The pattern of Bax expression in spermatogonia was similar to the $\mathrm{C}$ group. Bax was strongly detected in the cytoplasm of the Primary spermatocytes. Bax expression was also observed in some of the primary spermatocyte nuclei. Strong or moderate immunoreactivity was observed in cytoplasm of spermatids (Fig. 4). H-score assessment showed significant difference in stages of IV-VI, VII-VIII and IXXII $(p<0.05)$. No expression of Bax was observed in Sertoli cells or Leydig cells in control and three experimental groups. The results of $\mathrm{H}$-score assessments are reported in Fig. 9.

\section{Assessment of germ cell apoptosis}

In $\mathrm{C}$ group, spermatogonia showed a low frequancy of apoptosis in different stages (Fig. 5). In E1 group, TUNEL-reactivity was observed in some of the spermatogonia and primary spermatocytes (Fig. 6). There was no significant change in the AI between $\mathrm{E} 1$ and $\mathrm{C}$ group $(\mathrm{p}>0.05)$.

In E2 group, all types of germ cells showed TUNEL-positive reaction (Fig. 7). The AI of germ cells significantly increased in all stages of spermatogenic cycle apart from stages I-III. 

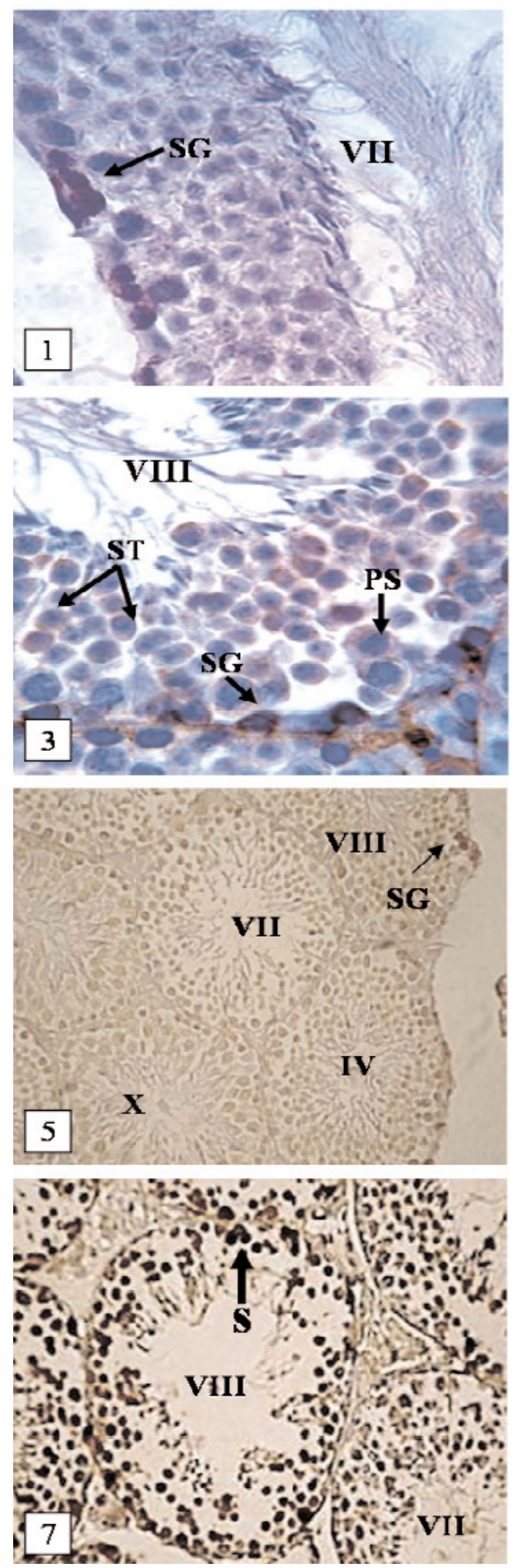
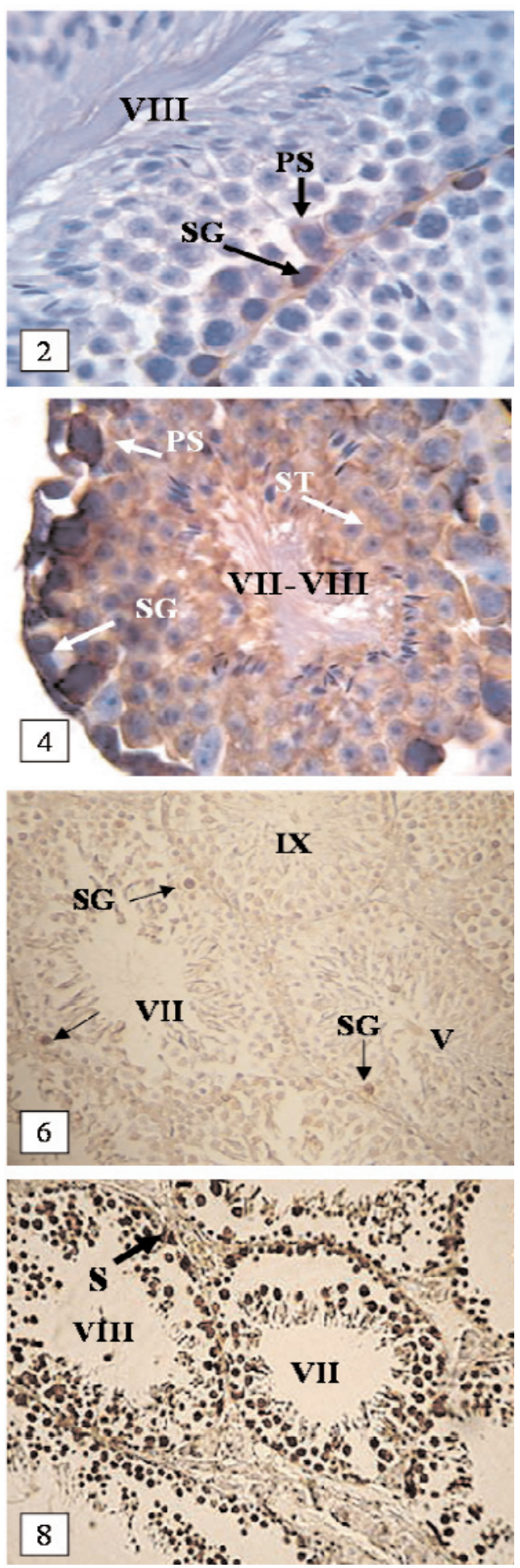

Fig. 1-8. Bax-immunodetection (Figs. 1-4) and TUNEL staining (Figs. 5-8) in the testis of control and experimental mice. Fig. I. Immunolocalization of $\mathrm{Bax}$ in $\mathrm{C}$ group;showing strong immunoreactivity only in spermatogonia (magnification $\times 1000$ ). Fig. 2 . Immunolocalization of Bax in E1 group; with strong immunoreactivity in spermatogonia and weak immunoreactivity in a few numbers of the primary spermatocytes (magnification $\times 1000)$. Fig. 3 . Immunolocalization of Bax in E2 group;showing strong immunostaining in spermatogonia with weak or moderate immunostaining in primary spermatocytes and spermatids (magnification $\times 1000)$. Fig. 4 . Immunolocalization of Bax in E3 group; showing strong immunostaining in spermatogonia and primary spermatocytes with strong or moderate immunoreactivity in spermatids (magnification $\times 200$ ). Fig. 5. TUNEL-positive reaction in $\mathrm{C}$ group;with positive staining in a few spermatogonia (magnification $\times 200$ ). Fig. 6. TUNEL-positive reaction in E1 group; some of the spermatogonia and spermatocytes are stained (magnification $\times 200$ ). Fig. 7. TUNEL-positive reaction in E2 group;showing positive reaction in all types of germ cells and sertoli cells (magnification $\times 250$ ). Fig. 8 . TUNEL-positive reaction in $\mathrm{E} 3$ group; with positive staining in majority of germ cells and Sertoli cells (magnification $\times 200$ ). SG: spermatogonia, PS: primary spermatocytes, ST: spermatid, S: Sertoli cell.
In E3 group, all types of germ cells showed TUNEL-positive staining (Fig. 8). The AI of germ cells significantly increased in all stages of spermatogenic cycle, particularly in stages of VII-VIII. The results of the AIs of germ cells reported in Fig 10.

Sertoli cells showed TUNEL staining in both E2 and E3 groups. AIs of Sertoli cells were significantly increased in E2 $(36.4 \pm 6.5 \%$ vs. $0 \% ; \mathrm{p}<0.01)$ and $\mathrm{E} 3$ $(44.8 \pm 9.3 \%$ vs. $0 \% ; \mathrm{p}<0.01)$

\section{Discussion}

In this study, we have shown that Dex causes increase of Bax expression in testicular germ cells. The expression of Bax protein in testicular germ cells was not random but was highly selective. Stages of VII-VIII were the most susceptible to apoptotic effects of Dex. Previous studies have shown that GC agents induce apoptosis in testis by decreasing the testosterone levels [13-15]. 


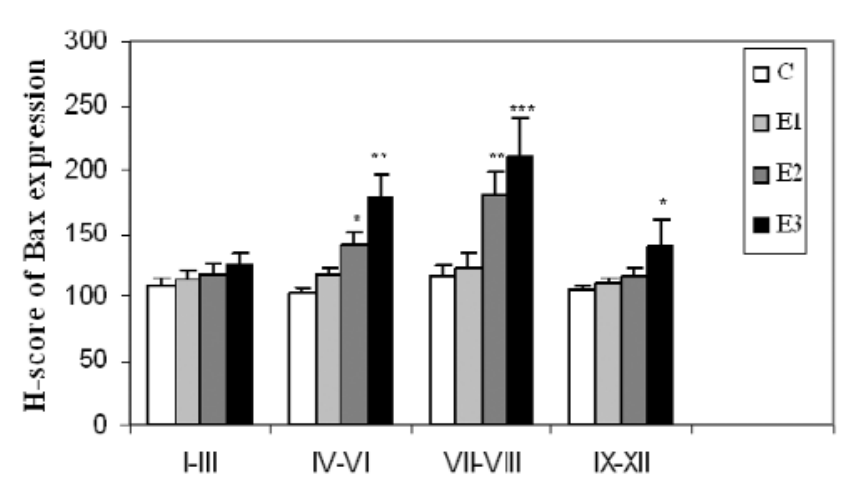

Fig. 9. Effects of Dex on Bax expression in different stages of spermatogenic cycle in the mouse. Values are expressed as Mean \pm SEM for 8 mice, $* \mathrm{p}<0.05, * * \mathrm{p}<0.01, * * * \mathrm{p}<0.001$ vs. $\mathrm{C}$ (control).

Sinha et al. have shown that deprivation of gonadotropins and testosterone by $\mathrm{GnRH}$ antagonist treatment is followed by a stage -specific increase in germ cell apoptosis [5]. A number of studies have shown that stages VII-VIII of the rat spermatogenic cycle exhibit the strongest levels of immunohistochemically detectable androgen receptore expression and are considered to be an androgen dependent [1618]. In this study we showed Dex can increase Bax expression in mouse testicular germ cells mainly at androgen dependent stages. After androgen withdrawal using Diethylstilbestrol, a strong estrogenic compound, the expression of Bax is up-regulated [19]. Thus, the induction of Bax may play a role in germ cell apoptosis following androgen withdrawal.

It is possible that high susceptibility to apoptosis evidenced by Bax expression does not necessarily commit all Bax-immunopositive cells to the apoptotic cell death. For this reason we applied the TUNEL method. This method is based on the detection of oligonucleosomal DNA fragments which are characteristic of cells in the later stages of the apoptotic process [20]. The measurement of apoptosis showed an increase in germ cell apoptosis after Dex treatment. The present data are consistent with the results of other investigators who demonstrated that Dex induces testicular germ cell apoptosis in rats [21].

The reason responsible for the increased apoptosis induced by Dex in germ cells is not known. Although the endocrine control in testicular function is clear, the complexity of the intratesticular events highlights the importance of regulatory mechanisms and interactions. Growth factors and cytokines are also involved in control mechanisms influencing testicular apoptosis through paracrine and autocrine mechanisms [22]. Intratesticular androgens, secreted by Leydig cells, also play an important paracrine role in preventing germ cell degeneration [23]. Bernier et al. showed that Dex and other synthetic GCs exert a direct inhibitory effect on testosterone production by Leydig cells in

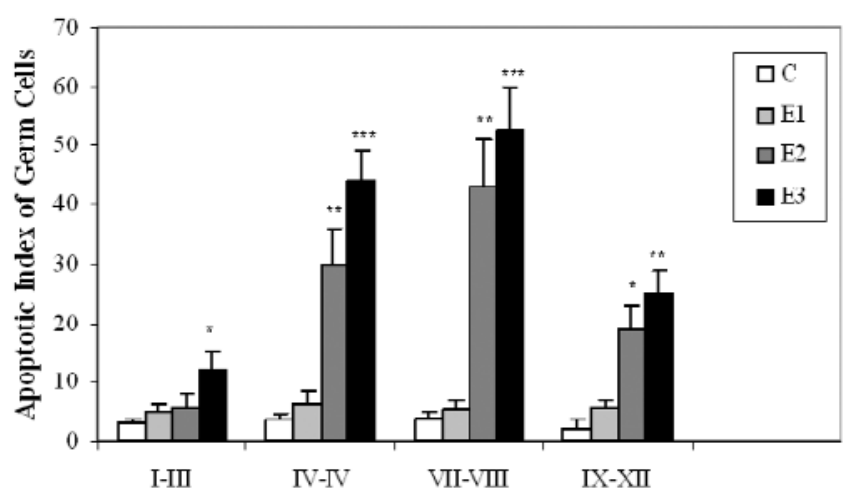

Fig. 10. Effects of Dex on apoptotic index (AI) of germ cells in different stages of spermatogenic cycle in the mouse. Values are expressed as Mean \pm SEM for 8 mice, ${ }^{*} \mathrm{p}<0.05,{ }^{* *} \mathrm{p}<0.01$, $* * * \mathrm{p}<0.001$ vs. $\mathrm{C}$ (control).

vitro [15]. In addition to the inhibition of androgen biosynthesis, excessive exposure to GC in rodents initiate apoptosis in rat Leydig cells [24].

In contrast previous studies, which showed Dex induces apoptosis in Leydig cell [24, 25], we demonstrated that Leydig cells were TUNEL negative in Dex treated mice. Thus, the increase of Bax expression in testicular germ cells is probably related to the inhibition effect of Dex on androgen biosynthesis in Leydig cells.

In present study, androgen-independent stages of spermatogenic cycle also showed TUNEL-reactivity and Bax expression in both E2 and E3 groups. Thus, we thought that the increasing of apoptosis can not be exclusively due to hormonal influence. In this study some of the Sertoli cells in Dex treated mice showed TUNEL positive reaction. Presence apoptosis in Sertoli cells may cause these cells loss their supporting action on germ cells, and this may stimulate different apoptotic signaling pathways in germ cells. There was no detectable Bax imunoreactivity in Sertoli cells, while these cells showed TUNEL-positive staining. This suggests that other apoptotic factors are involved in Dex induced apoptosis in testicular tissue.

In conclusion, our results suggest that increased Bax expression induced by Dex is related to induction of apoptosis in the mouse testicular germ cells. The mechanism by which Dex induces testicular germ cell apoptosis is not property known. Further experiments are needed to clarify the mechanisms of the effect of Dex on different apoptotic signaling pathways in testicular tissue.

Acknowledgements: This research was supported by a grant from the research council of the Ahwaz Jundi Shapour University of Medical Sciences.

\section{References}

[ 1] Julia CB. Glucocorticoids: exemplars of multi-tasking. Brit J Pharmacol. 2006;147:258-268. 
[ 2] Schmidt S, Ranier J, Ploner C, Presul E, Riml S, Kofler R. Glucocorticoid-induce apoptosis and Glucocorticoid resistance: molecular mechanisms and clinical relevance. Cell Death Differ. 2004;11:45-55.

[3] Grossfeld GD, Small EJ. Long-term side effects of treatment for testis cancer. Urol Clin North Am. 1998;25:503-515.

[4] Costabile RA, Spevak M. Cancer and male factor infertility. Oncology. 1998;12:557-562.

[ 5] Sinha AP, Rajavashisth TB, Sinha HI, Leu Y. Significance of apoptosis in the temporal and stage-specific loss of germ cells in the adult rat after gonadotropin-relasing hormone antagonist treatment. Biol Reprod. 1997;57:1193-1201.

[ 6] Sapolsky RM, Romero LM, Munck AU. How do glucocorticoids influence stress responses? Integrating permissive, suppressive, stimulatory, and preparative actions. Endocr Rev. 2000;21:55-89.

[ 7] Koji T, Hishikawa Y, Ando H, Nakanishi Y. Expression of Fas and Fas ligand in normal and ischemia-reperfusion testes: involvement of the Fas system in the induction of germ cell apoptosis in the damaged mouse testis. Biol Report. 2001;64: 946-954.

[ 8] Nagata S. Apoptosis by death factor. Cell. 1997;88:355-365.

[9] Emine E, Lisa O, Pierre-François C, Philippe J, Stephen M, François M. Mitochondria as the target of the pro-apoptotic protein Bax. Biochim Biophys Acta. 2006;4:1-11.

[10] Judit P, Elena B, Jose L, Xavier D, David L, Montserrat R. Immunohistochemical analysis of PTEN in endometrial carcinoma: a tissue microarray study with a comparison of four commercial antibodies in correlation with molecular abnormalities. Modern Path. 2005;18:719-727.

[11] Ariel R, Hila R, Edward Y, Jing XU, Robin H, Jean-Francois S, Robert FC. Resveratrol, a nutural aryl hydrocarbone receptore antagonist, protects sperm from DNA damage and apoptosis caused by benzo (a) pyrene. Reprod Toxicol. 2006;15: 479-486.

[12] Russell LD, Ettlin RA, Sinha AP, Clegg ED. Histological and histopathological evaluation of the testis. Cache River Press. 1990;3:87-96.

[13] Qiang D, Antoni S, Chantal M, Enmei N, Michael H, Mathew P. Rapid Glucocorticoid mediation of suppressed testosterone biosynthesis in male mice subjected to stress. J Androl. 2004; 25:973-981.

[14] Hardy MP, Gao HB, Dong Q, Chai WR. Stress hormone and male reproductive function. Cell Tissue Res. 2005;322:147-53.
[15] Bernier M, Gibb W, Collu R, Ducharme JR. Effect of glucocorticoids on testosterone production by porcine Leydig cells in primary culture. Can J Pharmacol. 1999;62(9):1166-9.

[16] Bremner WJ, Millar MR, Sharpe RM, Saunders PT. Immunohistochemical localization of androgen receptors in the rat testis: evidence for stage-dependent expression and regulation by androgens. Endocrinology. 1994;135:1227-1234.

[17] Shetty j, Marathe GK, Dighe RR. Specific immunoneutrealization of FSH leads to apoptotic cell death of pachytene spermatocytes and spermatogonial cells in the rat. Endocrinology. $1996 ; 137: 2179-2182$.

[18] Nisrine El, Fouziha I, Krisztian K, Sadok Y, Eric T, Benazir $\mathrm{S}$. Androgen- dependent apoptosis in male germ cells is regulated through the proto-oncoprotein CbI. Cell Biology. 2005;171(4):651-661.

[19] Kondo T, Goto S, Ihara Y, Urata Y, Ikedas S, Hishikawa Y, Izumi S, Shin M, Koji T. Diethylstilbestrol attenuates antioxidant activities in testis from male mice. Free Radic Res. 2002;36:957-966.

[20] Walker PR, Weaver VM, Lach B, Sikorsa M. Endonuclease activities associated with high molecular weight and internucleosomal DNA fragmentation in apoptosis. Exp Cell Res. 1994;213:100-106.

[21] Yawaza H, Sasagawa I, Nakada T. Apoptosis of testicular germ cells induced by exogenous glucocorticoid in rats. Hum Reprod. 2000;156:197-205.

[22] Billing H, Chun SY, Eisenhauver K, Husueh AJ. Gonadal cell apoptosis: hormone- regulated cell demise. Hum Reprod. 1996;2:103-17.

[23] Tapanainen JS, Tilly JL,Vihko KK, Hsueh AJ. Hormonal control of apoptotic cell death in the testis: gonadotropins and androgens as testicular cell survival factors. Mol Endocrinol. 1993; 7:643-50.

[24] Gao HB, Tong MH,Hu HY, You HY, Guo QS, Ge RS, Hardy MP. Glucocorticoid induces apoptosis in rat Leydig cells. Endocrinol. 2002;143:130-138.

[25] Gao HB, Tong MH,Hu HY, You HY, Guo QS, Ge RS, Hardy MP. Mechanism of glucocorticoid-induced Leydig cell apoptosis. Mol Cell Endocrinol. 2003;199:153-63.

Submitted: 5 January, 2009 Accepted after reviews: 13 March, 2009 
H. Mahmoud et al. 